doi: 10.22498/pages.24.2.81

\title{
Uncovering the past: multidisciplinary research on historic land cover and land use
}

\author{
Kees Klein Goldewijk1, M.-J. Gaillard ${ }^{2}$, K. Morrison ${ }^{3}$, M. Madella ${ }^{4}$ and N. Whitehouse ${ }^{5}$ \\ LandCover6k general meeting, Utrecht, The Netherlands, 14-16 June 2016
}

The LandCover6k working group brought together a group of 50 scientists from various disciplines (archaeology, history, geography, paleoecology, land-use and climate modeling) to discuss progress and future plans to improve historical land-use descriptions for Holocene climate modeling. It was the group's second general workshop - the first being the launch meeting in October 2015 (Gaillard et al. 2015). Alongside this, a first workshop of the historians and archaeologists group was held in 2015 (Morrison et al. 2016) and several regional workshops have also been organized. The aim of this second general workshop was to update the group on the progress made during the working group's first year of activities, and plan the next steps.

LandCover6k's rationale is that adequate incorporation of land cover in global and regional climate models is not satisfactory, and the effect of anthropogenic activities on global climate via bio-geochemical and bio-geophysical processes in the past is not yet fully understood (www.pastglobalchanges.org/ini/wg/landcover6k).

An overview of modeled Holocene land-use changes was presented, based on a new version of the HYDE database (Klein Goldewijk et al. 2011) - updated with better data,

irrigated and rain-fed cropland areas, and a distinction between managed pasture and extensive rangelands. The group reviewed patterns of HYDE, and regional comparisons were made with maps from historical geographers and archaeologists. One of the conclusions was that global allocation rules of HYDE do not perform well in the deep past due to a Eurocentric view of how people engaged in settlement and agriculture (expansion). Input from archaeologists and historians is clearly essential to this work and progress has already been made in southern and Central America, western Africa (see Fig. 1) and southern India. These regions are used as test cases of the land-use classification proposed by the LandCover6k working group (Morrison et al. 2016).

The group also reviewed progress made over the globe on regional pollen-based reconstructions of land cover) based on studies with the REVEALS model (Sugita 2007). REVEALS reconstructions for Europe except the Mediterranean and easternmost regions are already published (Trondman

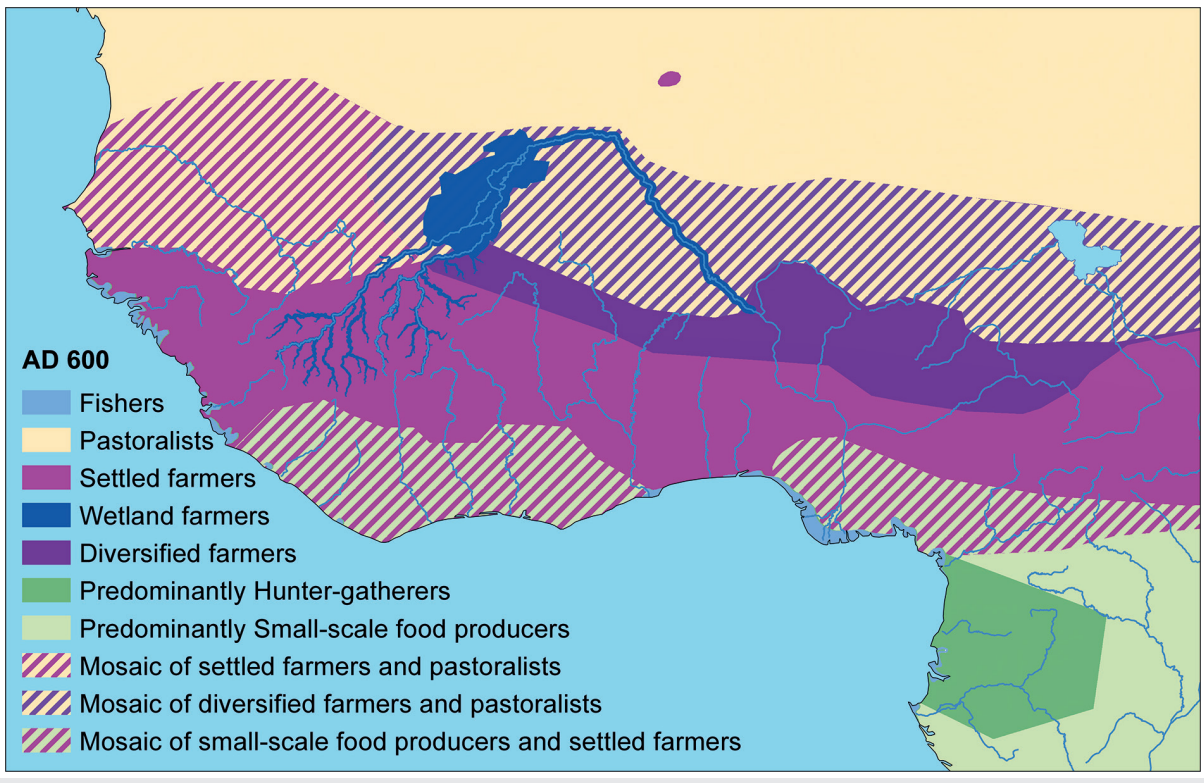

Figure 1: Livelihood distribution map for western Africa, AD 600 (Kay et al., unpublished data).

et al. 2015). REVEALS reconstructions will be available at the end of 2016 for parts of northern America, northern and temperate China, Siberia, and Cameroon.

Finally, current climate-modeling projects (e.g. within PMIP and CMIP) were reviewed and their needs in terms of past land-use and land-cover characteristics were discussed in the context of LandCover6k's aims and goals.

Participants agreed that focus should be on testing the global scale land-use categorization established by the archaeologists in volved in LandCover6k in southern America and southern India, and on the pollen-based reconstructions in regions where they are achievable within the relatively near future, i.e. northern America, southern and eastern Europe, Siberia, and India. Moreover, a case study is planned to incorporate empirical archaeological data from a single region into the HYDE system, in order to see whether this would produce a significant difference in modeled past agricultural patterns, and to evaluate whether that difference would significantly impact on climate change. It was also decided that Neotoma (www.neotomadb.org) will act as the major archive of all case studies from LandCover6k.

The LandCover6k working group will continue to be present at many international conferences, organizing sessions and presenting scientific results. Forthcoming events are the European Geosciences Union Assembly 2017, and PAGES' 5th Open Science Meeting (OSM). The third general workshop of LandCover6k will be held in conjunction with the OSM on 16-17 May 2017 in Zaragoza, Spain. For more details, see: http://www.pastglobalchanges.org/calendar/127-pages/1637-landcover6k-wshop-2017

\section{AFFILIATIONS}

${ }^{1}$ Copernicus Institute of Sustainable Development, Utrecht University, The Netherlands

Department of Biology and Environmental Science Linnaeus University, Kalmar, Sweden

${ }^{3}$ Department of Anthropology, University of Pennsylvania and the Museum of Archaeology and Anthropology, Philadelphia, USA

${ }^{4}$ Department of Humanities and ICREA, Universitat Pompeu Fabra, Barcelona, Spain

${ }^{5}$ School of Geography, Earth and Environmental Sciences, Plymouth University, UK

\section{CONTACT}

Kees Klein Goldewijk: c.g.m.kleingoldewijk@uu.nl

REFERENCES

Gaillard M-J et al. (2010) Clim Past 6: 483-499

Gaillard M-J et al. (2015) PAGES Mag 23: 81

Klein Goldewijk K et al. (2011) Glob Ecol Biogeogr 20 73-86

Morrison K et al. (2016) PAGES Mag 24: 40

Sugita S (2007) Holocene 17: 229-241

Trondman A-K et al. (2015) Glob Chang Biol 21: 676-697 